\title{
Prevalence of vitamin $D$ deficiency in patients with sickle cell disease in Bahrain
}

\author{
Adla B Hassan ${ }^{1,2}$, Taysir S Garadah ${ }^{1,2^{*}}$, Ahmed A Jaradadat ${ }^{2}$, \\ Abdulla Al Ajmi ${ }^{1}$, Mohamed E Alawi ${ }^{1}$, Reginald P Sequeira ${ }^{2}$ \\ ${ }^{1}$ Salmaniya Medical Complex, Ministry of Health, Manama, Kingdom of Bahrain. \\ ${ }^{2}$ College of Medicine and Medical Sciences, Arabian Gulf University, Manama, Kingdom of Bahrain \\ *Corresponding author E-mail: garadaht@hotmail.com
}

\begin{abstract}
Background: Patients with sickle cell disease (SCD) had a low serum level of vitamin D. The prevalence and the impact of this observation in SCD patient's in Bahrain is not clear.

Aim: To assess the prevalence of vitamin D deficiency (VDD) in homozygous patients with SCD, and to evaluate the clinical and biochemical predictors of occurrence of VDD in such patients.

Methods: We evaluated the vitamin D status in 70 patients with confirmed diagnosis of SCD and compared them with an age matched control group. Serum level of vitamin D, parathormone (PTH), calcium, phosphate, alkaline phosphatase, haemoglobin $(\mathrm{Hb})$, and uric acid were measured. Linear regression analysis was performed to assess the relation between PTH and vitamin D level. Multiple regression analysis was performed to assess the predictive value of gender, body mass index $(\mathrm{BMI})>24$, serum level of uric acid $>400$ umol/Land estimated glomerular filtration rate (eGFR) $<60$, for occurrence of vitamin D deficiency in patients with SCD.

Results: The mean age of the study group was $28.85 \pm 7.21$ years compared with the control of $29.91 \pm 4.3$ years, $\mathrm{p}=0.23$. There were 40 (57\%) female SCD patients compared with $39(55 \%)$ in the control. In patients with SCD, the serum level of vitamin D was sufficient, $>50 \mathrm{nmol} / \mathrm{L}$ in $4(5 \%)$ patients, insufficient $>27.5-\leq 50 \mathrm{nmol} / \mathrm{L}$ in $21(30 \%)$ patients, deficient $>12.5-\leq 27.5 \mathrm{nmol} / \mathrm{L} 35(50 \%)$ and profoundly deficient $\leq 12.5 \mathrm{nmol} / \mathrm{L}$ in $10(15 \%)$. In the control group, those with sufficient level of vitamin D were $53(75 \%)$, insufficient $21(30 \%)$ deficient of $10(15 \%)$ and none with profound deficiency, respectively. The serum level of PTH and alkaline phospahtase were significantly higher in the SCD group compared with control group. The eGFR, $\mathrm{Hb}$ and were significantly lower, serum level of uric acid was significantly higher ( $p<0.05$ but no significant difference between serum level of calcium or phosphate. Linear regression analysis showed inverse relation between VDD $(<25 \mathrm{nmol} / \mathrm{L})$ and PTH $(\mathrm{r}=-0.34, \mathrm{P}<0.001)$. Multiple regression analysis showed female gender, BMI>24, hyperurecemia and low eGFR were positive predictor of VDD in patients with SCD. Conclusion: The risk of vitamin D deficiency among subjects with SCD-SS was 3.8 folds greater than control subjects; the prevalence of VDD in SCD was $95 \%$ and $25 \%$ in the control patients without SCD. On linear regression analysis, there is a significant inverse relation between serum levels of vitamin D and PTH in SCD patients. The female gender, $\mathrm{BMI}>24$, hyperurecemia $>400 \mathrm{umol} / \mathrm{L}$ and low eGFR $<60$ were positive predictor of VDD in patients with SCD.
\end{abstract}

Keywords: Sickle cell disease, vitamin D deficiency, anemia, Bahrain.

\section{Introduction}

Sickle-cell disease (SCD) or sickle-cell anemia (SCA) is an autosomal recessive genetic blood disorder, characterized by red blood cells that assume an abnormal, rigid, sickle shape. Sickling of red blood cell (RBC) decreases the cells flexibility and results in a risk of various complications.[1]

In SCD, mutation results in the substitution of the amino acid valine for glutamic acid at position six of the beta chain leading to sickle cell hemoglobin ( $\mathrm{HbS})$.[2] As an autosomal recessive genetic blood disorder, the homozygous inheritance results in sickle cell disease. When HbSS is deoxygenated, it becomes relatively insoluble and forms aggregates of haemoglobin $(\mathrm{Hb})$ molecules within the RBC leading to vaso-occlusive complications.

Abnormal haemoglobin can be detected by haemoglobin electrophoresis, in which various types of haemoglobin move at varying speeds. The diagnosis can be confirmed with high-performance liquid chromatography (HPLC).[3] 
Sickle-cell disease may lead to various acute and chronic complications such as in SCA and SC crises that could be of many types including the vaso-occlusive crisis, aplastic crisis, sequestration crisis, hemolytic crisis, several of which have a high mortality rate.[1]

It was reported that the treatment with hydroxyurea decreases the frequency and severity of SCD attacks by reactivating fetal haemoglobin production in place of the HbS,[4] and shown to possibly increase survival time.[5]

Recent studies report a high prevalence of vitamin D deficiency (VDD) among patients with sickle cell disease (SCD), with a rates as high as $65-100 \%$ depending on the season.[6, 7] Despite this evidence, VDD remains under-recognized and under-treated in patients with sickle cell disease.

One report showed that children with SCA are 5.3 times more likely to develop vitamin-D deficiency than healthy African-American controls.[8] It is estimated that $65 \%$ of children with SCA had severe vitamin-D deficiency $(\leq 10$ $\mathrm{ng} / \mathrm{mL}$ ).[6] Despite these findings, vitamin-D levels are not routinely checked or treated in patients with sickle cell anemia.

The highest frequency of sickle cell disease was found in tropical regions, particularly sub-Saharan Africa, India and the Middle-East,[9] with prevalence of sickle-cell trait $(\mathrm{HbS})$ of $4.2 \%$ in Saudi Arabia and $0.26 \%$ of sickle cell disease (HbSS) with the highest prevalence in the Eastern province.[10]

A population-based study from Bahrain has confirmed a high prevalence of VDD, especially in females, that shows a seasonal variation.[11] In this study we assess the prevalence of VDD in patients with SCD (HbSS) in Bahrain and evaluate the clinical predictors of VDD in such patients.

\section{Materials, methods and setting}

The serum level of 25-hydroxy vitamin D (25-OHD) was evaluated in 70 patients with SCD over a three months period from 1.9.2012 to 1.12.2013. All patients were clinically in a steady state and were not experiencing any acute vaso-occlusive crisis (VOC) with no hospitalization for at least 3 months prior to the clinical evaluation. Patients were enrolled in the study if they have a long history of SCD (HbSS) with documented serum electrophoresis. Patient selection was consecutive from those who attend the hematology clinics in Salmaniya Medical Complex (SMC). SMC hospital is a government public hospital of 1100 beds with catchment area of 900,000 populations. A constitutional consent form was obtained and signed by each patient before enrollment in the study.

Patients were excluded if they were aged $>13$ years, have chronic renal disease, other chronic pain syndromes, such as juvenile rheumatoid arthritis, chronic liver disease, recent hospitalization $<3$ months, history of malignancy, known malabsorption or conditions associated with poor gastrointestinal absorption, patients currently on high dose vitamin D therapy and recent blood transfusion (<30 days).

Height, weight and calculated body mass index (BMI) of each patient was recorded. History of oral medications of hydroxyurea and hospitalization for SCD crisis in the last 12 months was documented. Each patient was examined for blood pressure and heart rate, signs of heart failure such as S3 gallop, raised jugular venous pressure, tender hepatomegaly and ankle edema.

Blood samples were withdrawn for the measurements of serum level of 25-hydroxy vitamin D, hemoglobin (Hb), chemical parameters for VD regulation such as calcium, phosphorus, PTH, as well as, alkaline phosphatase as a marker for bone turnover, uric acid and estimated glomerular filtration rate (eGFR).

Vitamin D deficiency (VDD) was defined as normal with vitamin D serum level of $>50 \mathrm{nmol} / \mathrm{L}$, deficient (VDD), if serum $25 \mathrm{OHD}$ between $>30-\leq 50 \mathrm{nmol} / \mathrm{l}$; severe VDD was defined as serum $25 \mathrm{OHD}>12.5-\leq 30 \mathrm{nmol} / \mathrm{l}$; and profound VDD was defined as serum $25 \mathrm{OHD} \leq 12.5 \mathrm{nmol} / 1$.[12] We defined vitamin D deficiency as sufficient $(>50 \mathrm{nmol} / \mathrm{L})$, insufficient $(>27.5-\leq 50 \mathrm{n} \mathrm{mol} / \mathrm{L})$, deficient $(>12.5-\leq 27.5 \mathrm{nmol} / \mathrm{L})$ and profoundly deficient $(\leq 12.5 \mathrm{nmol} / \mathrm{L}) .[12]$

Serum vitamin D was measured using Ultra Performance Liquid Chromatography-interfaced with tandem Mass Spectrometry (UPLC/MS/MS) at Al Jawhara Centre. We used commercially available vitamin D kits (Chromsystems Instruments \& Chemicals GmbH, Germany). Quantification of PTH in serum was performed by Enzyme-Linked Immunosorbent Assay (Creative Diagnostics, USA).

The serum level of calcium, phosphorus and alkaline phosphatase were measured using the auto-analyzer at Salmaniya Medical Complex (SMC). The control group patients were selected consecutively in the same period of time for agematched healthy patients who were attending SMC cardiac clinics for routine electrocardiogram and turned to be normal. 


\section{Statistical analysis}

The data was analyzed using the statistical package of social sciences (SPSS) version 17.1. All laboratory data of Hb, Vitamin D, Ca, PTH, phosphate and alkaline phosphatase, uric acid and estimated GFR are presented as mean \pm SD. Unpaired student-test was used to analyze the differences between the means.

Student's t-test was applied for continuous variables and Chi-square analysis for non-continuous data. Multiple logistic regression analysis was applied to calculate the odds ratio for different clinical and biochemical variables for the occurrence of VD deficiency in patients with sickle cell disease. All reported p-values are two tailed and p-value $<0.05$ was regarded as significant.

\section{Results}

Seventy patients with SCD were evaluated. The mean age of the study group was $28.85 \pm 7.21$ years and the control group $29.91 \pm 4.3$ years $(\mathrm{p}=0.23)$ with $40(57 \%)$ and $39(55 \%)$ female patients respectively."Table 1 " shows the clinical characteristics of patients with SCD and the control group.

Table 1: Clinical characteristics and the mean \pm SD of biometric values of patients with SCD and the control group.
\begin{tabular}{|l|l|l|l|}
\hline Parameters & SCD $\mathrm{n}=70$ & Control $\mathrm{n}=70$ & p-value \\
\hline Mean age (years) & $28.8 .5 \mp 7.21$ & $29.91 \mp 4.3$ & 0.23 \\
\hline Female & $40(57 \%)$ & $39(55 \%)$ & 0.76 \\
\hline BMI $\left(\mathrm{Kg} / \mathrm{M}^{2}\right)$ & $19.5 \mp 2.4$ & $24.04 \mp 2.86$ & 0.02 \\
\hline $\mathrm{Hb}(\mathrm{gm} / \mathrm{dl})$ & of $8.9 \mp 0.8$ & $13.01 \mp 1.12$ & 0.04 \\
\hline SBP $(\mathrm{mmHg})$ & $119 \mp 15$ & $120 \mp 12$ & 0.45 \\
\hline HR per minute & $80 \mp 3$ & $70 \mp 4$ & 0.03 \\
\hline
\end{tabular}

BMI: body mass index; Hb: hemoglobin; SBP: systolic blood pressure; HR: heart rate.

The SCD patients compared with control group had significantly lower BMI $(19.2 \pm 4)$, low hemoglobin (10.1 \pm 2 $\mathrm{gm} / \mathrm{dl})$, significantly higher heart rate $(81 \pm 4$ beat per minute) and similar systolic blood pressure in both groups. The mean values of biochemical markers in patients with SCD and the control group are shown in" table 2". The mean value of vitamin $\mathrm{D}$ is significantly lower of $26.8 \pm 7.4 \mathrm{vs} .35 .5 \pm 6.5 \mathrm{nmol} / \mathrm{L}, \mathrm{P}<0.01$.

Table 2: The mean value $\mp$ SD of biochemical parameters in patients with SCD and control group.

\begin{tabular}{|l|l|l|l|}
\hline Biochemical parameters & SCD $\mathrm{n}=70$ & Control $\mathrm{n}=70$ & p-value \\
\hline Vitamin D $(\mathrm{nmol} / \mathrm{L})$ & $26.08 \mp 7.4$ & $52.55 \mp 6.5$ & 0.001 \\
\hline $\mathrm{Hb}(\mathrm{gm} / \mathrm{dl})$ & $9.5 \mp 1.6$ & $12.4 \mp 1.9$ & $\mathrm{P}<0.05$ \\
\hline Alkaline phosphatase $(\mathrm{U} / \mathrm{L})$ & $190.7 \mp 78$ & $41.03 \mp 12.78$ & $\mathrm{P}<0.01$ \\
\hline $\mathrm{PTH}(\mathrm{pmol} / \mathrm{L})$ & $6.92 \mp 0.6$ & $4.13 \mp 0.34$ & $\mathrm{P}<0.001$, \\
\hline Calcium $\mathrm{mmol} / \mathrm{L}$ & $2.14 \mp 0.5$ & $2.12 \mp 0.3$ & $\mathrm{P}=0.36$ \\
\hline Phosphorus $(\mathrm{mmol} / \mathrm{L})$ & $1.29 \mp 0.3$ & $1.32 \mp 0.2$ & $\mathrm{P}=0.25$ \\
\hline Uric acid $(\mu \mathrm{mol} / \mathrm{dl})$ & $430.3 \mp 36$ & $340.6 \mp 44$ & $\mathrm{P}<0.05$ \\
\hline eGFR $\mathrm{ml} / \mathrm{min} / \mathrm{M}^{2}$ & $67.3 \mp 7.8$ & $92.5 \mp 63.94$ & $\mathrm{P}<0.05$ \\
\hline
\end{tabular}

eGFR: estimated glomerular filtration rate; PTH: Parathormone; SCD: Sickle cell disease.

Haemoglobin level in SCD patients was significantly lower $9.5 \pm 1.6 \mathrm{gm} / \mathrm{dl} v s .12 .4, \pm 1.8$ (p <0.05), calcium and phosphorus were slightly lower but of no statistical significance. The serum level of PTH hormone was significantly higher in SCD patients $(4.5 \pm 1.1$ vs. $2.5 \pm 1.2 \mathrm{pmol} / \mathrm{L}, \mathrm{p}<0.05)$ with a significantly higher level of alkaline phosphatase compared with control of $122.4 \pm 14.4$ vs. $54.4 \pm 12.5(\mathrm{p}<0.05)$.

"Table 3" showed that the SCD patients with deficient serum level of $<27.5 \mathrm{nmol} / \mathrm{L}$ compared with insufficient serum level of $>27.5 \mathrm{nmo} / \mathrm{L}$ had significantly high PTH and high alkaline phosphatase.

In SCD patients there were $24(53 \%)$ in the deficient group taking hydroxyurea medication and $12(56 \%)$ were in the insufficient group indicating the lack of influence of hydroxyurea treatment on vitamin $\mathrm{D}$ level.

Linear regression analysis showed inverse relation between VDD $<27.5 \mathrm{nmol} / \mathrm{L}$ and PTH $(\mathrm{r}=-0.34, \mathrm{p}<0.001)$. Multiple regression analysis showed female gender $>18$ years of age as positive predictors of VDD in SCD with odds of female 
gender 2.2 (95\% CI:1.8-2.6; p=0.03), BMI >24 of $1.2(95 \% \mathrm{CI}: 0.8-1.6, \mathrm{p}=0.02$ ), hyperuricemia $>400 \mathrm{mg} / \mathrm{L} 1.0(95 \%$ CI:0.8-1.2, p<0.04) and low eGFR (<60) of 0.8 (95\% CI: 0.7-0.9, p<0.045) .

The serum level of vitamin D in SCD patients and the control groups is depicted in "Figure 1". Patients with sufficient serum level of VD of $>50 \mathrm{nmol} / \mathrm{L}$ were $4(0.06 \%)$ versus $53(76 \%)$ patients in the control group and those with insufficient serum level of $>30-\leq 50 \mathrm{nmol} / \mathrm{L}$ were $21(30 \%) v s .7$ (10\%) respectively. The serum level of VD deficiency of $>12.5-\leq 30 \mathrm{nmol} / \mathrm{L}$ was observed in 35(50\%) versus $10(14 \%)$ in the control but profound deficiency of $<12.5 \mathrm{nmol} / \mathrm{L}$ was seen in $10(14 \%)$ in SCD patients and none in the control group.

Table 3: Vitamin D serum level in patients with SCD of $<27.5 \mathrm{nmol} / \mathrm{L}$ or more than $27.5 \mathrm{nmol} / \mathrm{L}$.

\begin{tabular}{|l|l|l|l|}
\hline Parameters & $\mathrm{VD} \leq 27.5 \mathrm{~N}=45$ & $\mathrm{VD}>27.5 \mathrm{~N}=25$ & $\mathrm{P}$ value \\
\hline Alkaline phosphatase (U/L) & $140.5 \mp 24$ & $44.5 \mp 16$ & $<.001$ \\
\hline PTH (pmol/L) & $6.8 \mp 0.8$ & $4.2 \mp 0.4$ & $<0.01$ \\
\hline Treatment with hydroxyurea & $24(53 \%)$ & $14(56 \%)$ & $=0.65$ \\
\hline
\end{tabular}

PTH: parathormone

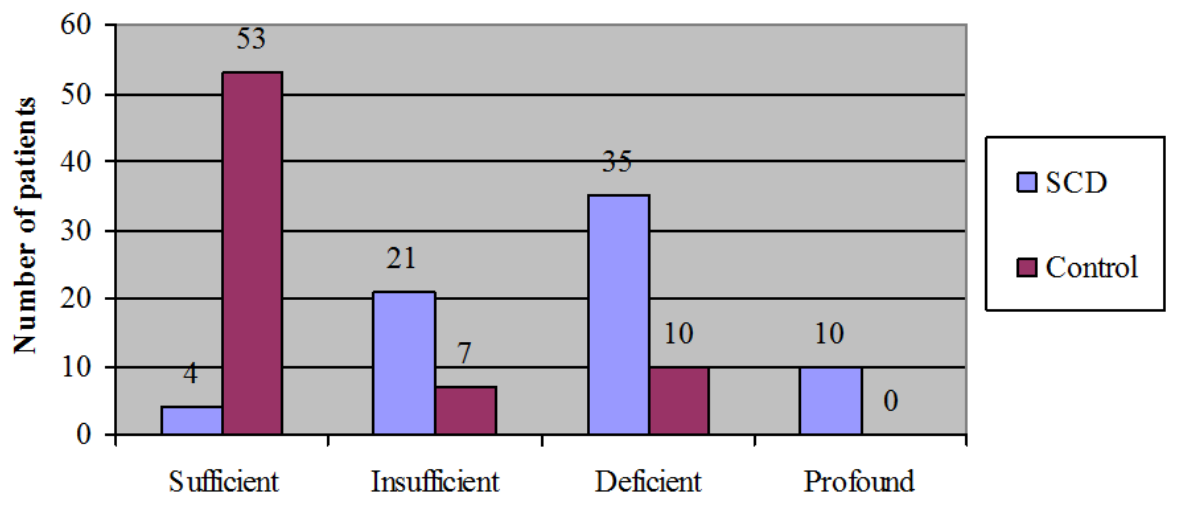

Serum level of Vitamin D

Fig. 1: The status of serum level vitamin $\mathrm{D}$ in patients with and without sickle cell disease.

\section{Discussion}

The study evaluated the prevalence of vitamin D deficiency in 70 patients with SCD. The prevalence of low serum level of vitamin $\mathrm{D} \leq 50 \mathrm{nmol} / \mathrm{L}$ was $(94 \%)$ in total. Thirty percent of patients had vitamin D deficiency of $27.5-50 \mathrm{nmol} / \mathrm{L}$ and $64 \%$ had severe deficiency of $<27.5 \mathrm{nmol} / \mathrm{L}$. This finding is in keeping with two recent reports about VDD in patients with SCD. First report by Goodman et al.,[13] studied 148 patients with SCD and found $98 \%$ of patients had low (suboptimal) serum level $(<30 \mathrm{ng} / \mathrm{ml})$ and $60 \%$ had severe VD deficiency of $<10 \mathrm{ng} / \mathrm{ml}$. The second study by Arlet et al.[14] was conducted on 56 patients with SCD found that VDD was detected in $26(46 \%)$ patients with severe deficiency and another $26(46 \%)$ with insufficiency.

Rovner et al., in their study reported 61 patients with homozygous SS sickle cell disease; vitamin D status was compared with healthy African-American children living in the same geographic area. Ninety-three percent of subjects with SCD-SS and $90 \%$ of healthy subjects had vitamin D insufficiency [25-hydroxy vitamin D $<30 \mathrm{mg} / \mathrm{mL}$ ]. The risk of vitamin D deficiency among subjects with SCD-SS was 5.3 (95\% CI: 2.5, 8.2) times greater than control subjects.[15] Erkal et al., studied 994 patients with general bone pain regarding the prevalence of VDD and concluded that $75 \%$ had VDD of $<50 \mathrm{nmol} / \mathrm{L}$. Female with VDD $<25 \mathrm{nmol} / \mathrm{L}$ were $30 \%$ compared with male $19 \%$. The most positive predictor of VDD was the female gender, high body mass index, and the lack of sun exposure, living at high altitude and wearing scarf.[16]

The very low level of VD in SCD is ubiquitous and it seems of multifactorial origin. It may be of cultural, behavioral and environmental factors all together. The level of high PTH and high level of alkaline phosphatase in VD deficient patients with SCD indicate that this finding mostly secondary to low serum calcium due to VD deficiency. On regression analysis there was a significant inverse relationship between PTH serum level and the level of VDD in this study. Such a finding was also shown previously by Boonen et al, [17] and Rodan et al. [18]

Cashman et al, had conducted a study on healthy adolescents, and concluded that individuals with VD level $>74.1$ nmol/L had a significantly lower PTH and normal bone turnover markers compared with those of low VD status <46.4 nmol/L with higher PTH.[19] 
Recent report showed that high BMI and female gender were positive predictors of VDD in SCD patients. In this study female gender, $\mathrm{BMI}>24$, hyperurecemia $>400 \mathrm{umol} / \mathrm{L}$ and low eGFR $<60$ were positive predictor.

In the control group the mean value of VDD was of $52 \mathrm{nmol} / \mathrm{L},(\mathrm{n}=70)$ compared with $26 \mathrm{nmol} / \mathrm{L}$ in $\mathrm{SCD}$ patients. Those who had VDD were of $24 \%$ versus $94 \%$ in SCD patients. The majority of control patients had a normal serum level of VD of $>50 \mathrm{nmol}, \mathrm{n}=53$ and only 4 patients had normal level in SCD group.[20]

The low status of serum level of VD in the control group was surprising and may need further evaluation and follow up to assess the seasonal impact, cultural differences, nutritional factors and exposure to sunlight.

There are other important findings in this study such as the significant high heart rate in SCD patients compared with control patients. The positive predictive value of high BMI of vitamin D deficiency is in agreement with another report of Saintonge $\mathrm{S}$ et al, where an inverse relation was found between the High BMI and the VD.[21] The significance of low $\mathrm{Hb}$ in patients with SCD may be explained partly by the state of chronic low hemoglobin due to long-standing hypoxia.

\section{Limitations of the study}

The study focused on the prevalence of vitamin D in SCD patients in a single centre. There was no clinical evaluation and correlation for the presence or absence of muscle pain. Thus, further study is required to clarify the clinical outcomes.

\section{Conclusion}

The risk of vitamin D deficiency among subjects with SCD-SS was 3.9 times greater than the control subjects. The prevalence of VDD in SCD was $94 \%$ and $24 \%$ in the control patients without SCD. The mean serum level of PTH was significantly greater in SCD patients with the marker of bone turnover. PTH had an inverse linear relationship to serum level of vitamin D.

\section{Acknowledgements}

This study is supported by a grant (No.95) from the Arabian Gulf University, Bahrain. We are also very grateful to Sister Aziza Ahmed who helped to call each patient and collect blood samples.

\section{References}

[1] Platt OS, Brambilla DJ, Rosse WF, Milner PF, Castro O, Steinberg MH, et al. Mortality in sickle cell disease. Life expectancy and risk factors for early death, The New England journal of medicine,330(23)(1994):1639-44.

[2] Ingram VM. A case of sickle-cell anaemia: a commentary on 'Abnormal Human Haemoglobins. I. The Comparison of Normal Human and Sickle-Cell Haemoglobins by 'Fingerprinting" with II. The Chymotryptic Digestion of the Trypsin-resistant 'Core' of Haemoglobins A and S and III. The Chemical Difference Between Normal and Sickle Cell Haemoglobins,Biochimica et biophysica acta,1000,(1989)147-50.

[3] Clarke GM, Higgins TN. Laboratory investigation of hemoglobinopathies and thalassemias: review and update. Clinical chemistry,46(2000), 1284-90.

[4] Charache S, Terrin ML, Moore RD, Dover GJ, Barton FB, Eckert SV, et al. Effect of hydroxyurea on the frequency of painful crises in sickle cell anemia. Investigators of the Multicenter Study of Hydroxyurea in Sickle Cell Anemia, The New England journal of medicine,332(20)(1995)1317-22.

[5] Steinberg MH, Barton F, Castro O, Pegelow CH, Ballas SK, Kutlar A, et al. Effect of hydroxyurea on mortality and morbidity in adult sickle cell anemia: risks and benefits up to 9 years of treatment. JAMA : the journal of the American Medical Association, 289(13)(2003)1645-51.

[6] Buison AM, Kawchak DA, Schall J, Ohene-Frempong K, Stallings VA, Zemel BS. Low vitamin D status in children with sickle cell disease. The Journal of pediatrics, $145(5)(2004) 622-7$.

[7] Chapelon E, Garabedian M, Brousse V, Souberbielle JC, Bresson JL, de Montalembert M. Osteopenia and vitamin D deficiency in children with sickle cell disease, European journal of haematology,83(6)(2009)572-8.

[8] Rovner AJ, Stallings VA, Kawchak DA, Schall JI, Ohene-Frempong K, Zemel BS. High risk of vitamin D deficiency in children with sickle cell disease,Journal of the American Dietetic Association,108(9)(2008)1512-6.

[9] Weatherall DJ, Clegg JB. Inherited haemoglobin disorders: an increasing global health problem. Bulletin of the World Health Organization,79(8)(2001)704-12.

[10] Jastaniah W. Epidemiology of sickle cell disease in Saudi Arabia. Annals of Saudi medicine, 31(3)(2011)289-93.

[11] Golbahar J, Al-Saffar N, Altayab Diab D, Al-Othman S, Darwish A, Al-Kafaji G. Predictors of vitamin D deficiency and insufficiency in adult Bahrainis: a cross-sectional study, Public health nutrition.(3) (2013)1-7. 
[12] Holick MF. Vitamin D deficiency. The New England journal of medicine,357(3)(2007)266-81

[13] Goodman BM, 3rd, Artz N, Radford B, Chen IA, Prevalence of vitamin D deficiency in adults with sickle cell disease. Journal of the National Medical Association, 102(4)(2010):332-5.

[14] Arlet JB, Courbebaisse M, Chatellier G, Eladari D, Souberbielle JC, Friedlander G, et al. Relationship between vitamin D deficiency and bone fragility in sickle cell disease: a cohort study of 56 adults, Bone,52(1)(2013)206-11.

[15] Rovner AJ, Stallings VA, Schall JI, Leonard MB, Zemel BS. Vitamin D insufficiency in children, adolescents, and young adults with cystic fibrosis despite routine oral supplementation, The American journal of clinical nutrition, 86(6)92007)1694-9.

[16] Erkal MZ, Wilde J, Bilgin Y, Akinci A, Demir E, Bodeker RH, et al. High prevalence of vitamin D deficiency, secondary hyperparathyroidism and generalized bone pain in Turkish immigrants in Germany: identification of risk factors. Osteoporosis international : a journal established as result of cooperation between the European Foundation for Osteoporosis and the National Osteoporosis Foundation of the USA, 17(8)(2006)1133-40.

[17] Boonen S, Aerssens J, Dequeker J. Age-related endocrine deficiencies and fractures of the proximal femur. II implications of vitamin D deficiency in the elderly. The Journal of endocrinology,149(1)(1996)13-7.

[18] Rodan SB, Rodan GA, Simmons HA, Walenga RW, Feinstein MB, Raisz LG. Bone resorptive factor produced by osteosarcoma cells with osteoblastic features is PGE2. Biochemical and biophysical research communications,102(4)(1981)1358-65.

[19] Cashman KD, Hill TR, Cotter AA, Boreham CA, Dubitzky W, Murray L, et al. Low vitamin D status adversely affects bone health parameters in adolescents, The American journal of clinical nutrition,87(4)(2008)1039-44.

[20] McSheehy PM, Chambers TJ. Osteoblastic cells mediate osteoclastic responsiveness to parathyroid hormone, Endocrinology,118(2)(1986)824-8.

[21] Saintonge S, Bang H, Gerber LM. Implications of a new definition of vitamin D deficiency in a multiracial us adolescent population: the National Health and Nutrition Examination Survey III. Pediatrics, 123(3)(2009)797-803. 